\title{
ON THE MULTIPLICATIVE SUM ZAGREB INDEX OF GRAPHS WITH SOME GIVEN PARAMETERS
}

\author{
JiAnWEI DU AND XiAOLING SUN
}

Abstract. The multiplicative sum Zagreb index of a graph $G$ is the product of the sums of degrees of pairs of adjacent vertices. In this work, we obtain the maximum values of the multiplicative sum Zagreb indices with fixed number of cut edges, or cut vertices, or edge connectivity, or vertex connectivity of graphs. Furthermore, we characterize the corresponding extremal graphs.

Mathematics subject classification (2010): 05C07, 92E10.

Keywords and phrases: Multiplicative sum Zagreb index, cut edge, cut vertex, vertex connectivity, edge connectivity.

\section{REFERENCES}

[1] J. A. Bondy And U. S. R. Murty, Graph theory with applications, Elsvier, New York, 1976.

[2] K. XU AND K. CH. DAS, Trees, unicyclic, and bicyclic graphs extremal with respect to multiplicative sum Zagreb index, MATCH Commun. Math. Comput. Chem., 68, (2012), 257-272.

[3] M. Eliasi, A. Iranmanesh And I. Gutman, Multiplicative versions of first Zagreb index, MATCH Commun. Math. Comput. Chem., 68, (2012), 217-230.

[4] Z. Du AND B. ZHou, On the Estrada index of graphs with given number of cut edges, Electron. J. Linear Algebra, 22, (2011), 586-592.

[5] K. FAng AND J. Shu, On graphs with cut vertices and cut edges, Acta Math. Sin., 30 (2014) 539-546.

[6] R. Todeschini And V. Consonni, Handbook of Molecular Descriptors, Wiley-VCH, Weinheim, 2000.

[7] I. Gutman and B. Furtula (Eds.), Novel Molecular Structure Descriptors - Theory and Applications I, Univ. Kragujevac, Kragujevac, 2010.

[8] I. Gutman AND B. Furtula (Eds.), Novel Molecular Structure Descriptors - Theory and Applications II, Univ. Kragujevac, Kragujevac, 2010.

[9] M. AZARI AND A. IRANMANESH, Some inequalities for the multiplicative sum Zagreb index of graph operations, J. Math. Inequal., 9, (2015), 727-738.

[10] Božović, Ž. K. KoviJanić AND G. Popivoda, Chemical trees with extreme values of a few types of multiplicative Zagreb indices, MATCH Commun. Math. Comput. Chem., 76, (2016), 207-220.

[11] I. GutMAN AND N. TRinAJSTIĆ, Graph theory and molecular orbitals. III. Total $\pi$-electron energy of alternant hydrocarbons, Chem. Phys. Lett., 17, (1972), 535-538.

[12] R. TODESCHINI AND V. CONSONNI, New local vertex invariants and molecular descriptors based on functions of the vertex degrees, MATCH Commun. Math. Comput. Chem., 64, (2010), 359-372.

[13] H. LiU, M. Lu AND F. Tian, On the spectral radius of graphs with cut edges, Linear Algebra Appl., 389, (2004), 139-145.

[14] R. Wu, H. CHEN AND H. DENG, On the monotonicity of topological indices and the connectivity of a graph, Appl. Math. Comput., 298, (2017), 188-200.

[15] Q. ZhaO AND S. C. LI, On the maximum Zagreb indices of graphs with $k$ cut vertices, Acta Appl. Math., 111, (2010), 93-106.

[16] X. Li And Y. FAn, The connectivity and the Harary index of a graph, Discret. Appl. Math., 181, (2015), 167-173.

[17] S. CHEN AND W. LiU, Extremal Zagreb indices of graphs with a given number of cut edges, Graphs Comb., 30, (2014), 109-118. 
[18] Y. Feng, X. HU AND S. LI, On the extremal Zagreb indices of graphs with cut edges, Acta Appl. Math., 110, (2010), 667-684. 